\title{
Aldo-Keto Reductase Family 1 Member C1
}

National Cancer Institute

\section{Source}

National Cancer Institute. Aldo-Keto Reductase Family 1 Member C1. NCI Thesaurus. Code C105419.

Aldo-keto reductase family 1 member C1 (323 aa, $37 \mathrm{kDa}$ ) is encoded by the human AKR1C1 gene. This protein is involved in the conversion of progesterone to its inactive form and may have a role in the transport of bile. 